\title{
Video-assisted transthoracic liver resection in patients with marginal liver function: a retrospective cohort study
}

\author{
Ryong Ho Jung', Hyug Won Kim², Sam-Youl Yoon ${ }^{1}$ \\ 'Department of Surgery, Sanggye Paik Hospital, Inje University College of Medicine, Seoul; \\ ${ }^{2}$ Department of Surgery, Hallym Sacred Heart Hospital, Anyang, Korea
}

Purpose: Laparoscopic hepatectomy has been widely performed by hepatobiliary surgeons for malignancy of liver and gained wide acceptance for various liver tumors, thanks to advances in surgical techniques and devices. But, there are some challenges for right side tumor in patients of cirrhotic liver. Especially, tumor located in right upper area is difficult for wedge resection in patients with marginal liver function, because trans-abdominal approach requires normal parenchymal dissection. Radiofrequency wave ablation is also difficult for such a lesion. So, we demonstrate unique technique of video-assisted transthoracic liver resection $(V T L R)$ for overcome right upper side tumor abutting diaphragm.

Methods: Four patients underwent VTLR. Four ports in right chest wall were created by a chest surgeon and diaphragm was open. Then traction of the diaphragm was done by suture. After exposure of liver surface, tumor localization was done by ultrasound. The mass excision was done by ultrasonic shear.

Results: Four patients were discharged without complications within 11.3 days (range, $6-15$ days). On average, patients started to consume a normal diet on an average of 2.4 days (range, 1-4 days).

Conclusion: VTLR is could be performed by an experienced surgeon and chest surgeon for right upper liver malignancy abutting diaphragm in patient of marginal liver function.

Keywords: Hepatocellular carcinoma, Video-assisted transthoracic, Liver resection

\section{INTRODUCTION}

Laparoscopic liver resection (LLR) has been very common due to the development of techniques and medical devices since 1992. In 2008, experts in liver surgery established the "Louisville Statement," a set of guidelines about the rapidly growing area of mini-

Received: Dec 7, 2021 Accepted: Dec 22, 2021

Correspondence to: Sam-Youl Yoon

Department of Surgery, Sanggye Paik Hospital, Inje University College of

Medicine, 1342 Dongil-ro, Nowon-gu, Seoul 01757, Korea

Tel: +82-2-950-1114, Fax: +82-50-7077-4445

E-mail: cdgx287@gmail.com

ORCID: Ryong Ho Jung (https://orcid.org/0000-0001-5069-0159), Hyung Won Kim (https://orcid.org/0000-0003-2329-2248), Sam-Youl Yoon (https://orcid.org/00000002-4624-1497)

Copyright (@) 2021 Korean Society of Surgical Oncology

This is an Open Access article distributed under the terms of the Creative Commons Attribution Non-Commercial License (http://creativecommons.org/licenses/by-nc/4.0) which permits unrestricted non-commercial use, distribution, and reproduction in any medium, provided the original work is properly cited. mally invasive liver resection. The number of LLRs reported has consistently increased, especially since 2009. Although minor LLRs have been performed usually in clinical practice, reports of major and anatomic LLRs have increased sharply [1,2]. Some specialized centers have reported favorable and competitive outcomes of LLR compared to open liver resection (OLR). Liver cancer lesions located in the right upper lobe of the liver or invading the diaphragm are difficult subjects for LLR. Moreover, in the case of a patient with cirrhosis of Child $\mathrm{B}$ and mild ascites, hepatic resection of segment 7 or 8 is more difficult. In this case, LLR unnecessarily removes a large amount of liver parenchyma, reducing the remnant liver volume and also OLR may cause damage to the abdominal wall and cavernous reticulum, resulting in more severe cirrhosis and ascites, and eventually liver failure.

In patients with marginal liver function, no further radiofrequency treatment or trans-arterial chemoembolization (TACE) was possible, and LLR or OLR was not possible. Hepatectomy was attempted through video-assisted transthoracic liver resection 
(VTLR). We report a case of liver resection using the modified Kelly fracture method using Harmonic Scalpel (Ethicon Endo-Surgery, Inc., Cincinnati, OH, USA) ultrasonic shears.

\section{METHODS}

All of the procedures were in accordance with the ethical standards of the responsible committees on human experimentation (institutional and national ) and with the 1964 Declaration of Helsinki

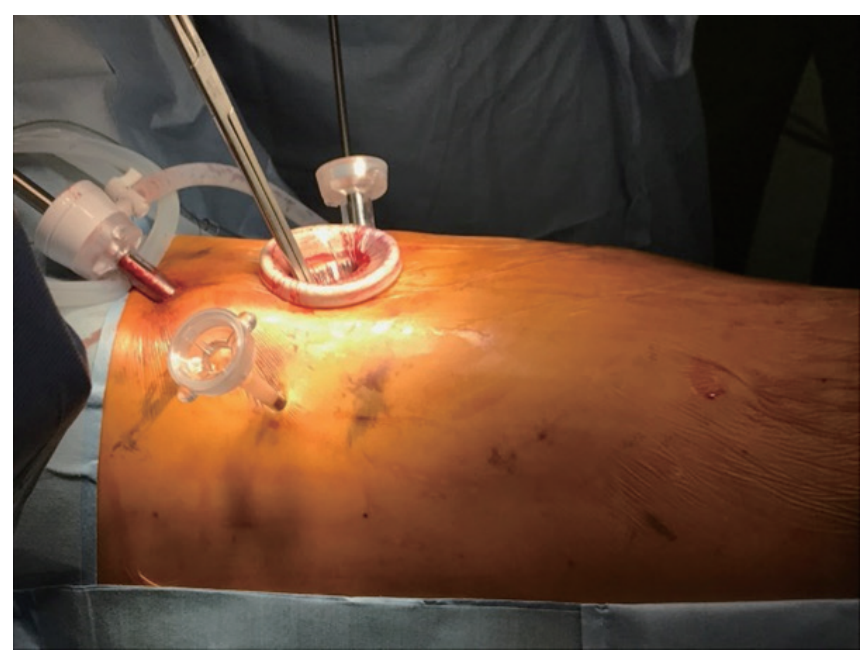

Fig. 1. Position of video-assisted transthoracic liver resection.
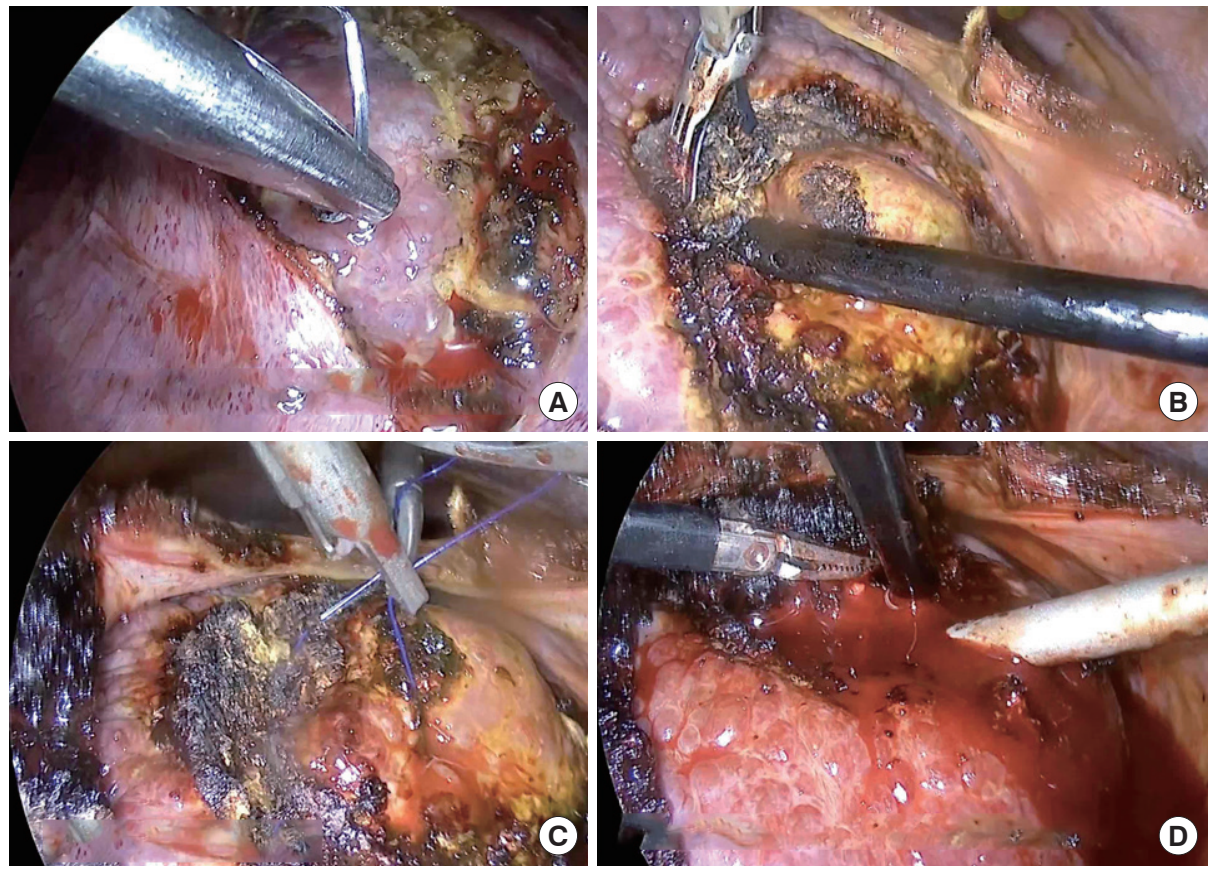

Fig. 2. Procedure of video-assisted transthoracic liver resection. (A) Diaphragm 3-point traction was done. (B, C) After tagging suture for counter traction, the counter traction was performed by assistant. (D) Attention for bleeding from the hepatic vein is required during the modified Kelly fracture method by ultrasonic shear. 
Table 1. Clinicopathologic data of the patients enrolled in the current study

\begin{tabular}{lc}
\hline Variable & VTLR $(\mathrm{n}=4)$ \\
\hline Age (yr) & $52.3(49-63)$ \\
Female/male (ratio) & $1 / 3(0.33)$ \\
Liver disease & \\
HBV & $3(75)$ \\
Drug-induced LC & $1(25)$ \\
ICG 15 (\%) & $12.3(9-15)$ \\
INR & $1.02(0.8-1.3)$ \\
Total bilirubin (mg/dL) & $1.03(0.8-1.3)$ \\
Albumin (g/dL) & $3.64(3.3-4.2)$ \\
CTP score & \\
A & $3(75)$ \\
B & $1(25)$ \\
Tumor location & \\
Segment 7 & $2(50)$ \\
Segment 8 & $2(50)$ \\
\hline
\end{tabular}

Values are presented as median (interquartile range) or number (\%). $V T L R$, video-assisted transthoracic liver resection; HBV, hepatitis $B$ virus; $L C$, liver cirrhosis; ICG 15, indocyanine green retention rate at 15 minutes; INR, international normalized ratio; CTP score, Child-Turcotte-Pugh score.

\section{RESULTS}

This study included three hepatocellular carcinoma patients and one metastatic liver malignancy from colon cancer who underwent VTLR from March 2017 to February 2020. Their mean age was 52.3 years (range, 49-63 years). The underlying liver disease was hepatitis B virus in three patients (75\%) and drug-induced hepatitis in one patient (25\%). The mean indocyanine green retention rate at 15 minutes (ICG 15) of the patient group was 12.3\% (range, 9\%-15\%). Preoperative serum international normalized ratio, total bilirubin, and albumin results were 1.02 (range, 0.8-1.3), $1.03 \mathrm{mg} / \mathrm{dL}$ (range, $0.8-1.3 \mathrm{mg} / \mathrm{dL}$ ), and $3.64 \mathrm{~g} / \mathrm{dL}$ (range, 3.3-4.2 $\mathrm{g} / \mathrm{dL}$ ), respectively. According to the Child-Pugh classification, three patients ( $75 \%$ ) belonged to class A, and one (25\%) was placed in class B. On average, patients started to consume a normal diet on the average of 2.4 days (range, 1-4 days), and were discharged after an average of 11.3 days (range, 6-15 days) of hospitalization. VTLR was carried out in segment 7 in two cases and in segment 8 in two cases (Table 1).

\section{DISCUSSION}

LLR has been continuously developing since 2008. Laparoscopic resection of tumors located in the left lobe or superficial hepatic lobe is relatively easy. In the case of a tumor that is biased to the right, resection is relatively easy. However, laparoscopic resection of tumors located in the posterior segment, especially in the right upper lobe that invades the diaphragm, is difficult. This is a study to evaluation the technique of performing VTLR for liver malignancy located in right upper area with marginal liver function.

Several studies have shown the usefulness of thoracoscopic liver resection. Excessive bleeding is a major problem in cirrhotic liver resection, and many studies have used coagulation techniques such as microwave tissue coagulation, TissueLink monopolar sealer, or radiofrequency waves $[3,4]$. In this study, ultrasound was performed before incision of the diaphragm to determine the location of the liver lesion, and thoracoscopic liver resection was performed using the Kelly fracture method using an ultrasonic cutting machine rather than the radiofrequency ablation method. An ultrasonic cutting machine made an incision space for the liver parenchyma through ultrasonic cavitation, and the exposed Glissonean pedicle and hepatic vein were ligated with clips.

In determining the location of the sub-diaphragm tumor, in this study, the location was determined using intraoperative ultrasound before incision of the diaphragm. Recently, intervention-guided fluorescence imaging technique or indocyanine green under infrared light methods to confirm the location of liver tumors are also expected to be utilized [5].

Hepatic resection has been proven to be an effective treatment modality for the treatment of hepatocellular carcinoma and metastatic colorectal cancer [6]. In this study, patients with marginal liver function in the upper right liver segment did not have an accessible hepatic artery through frequent TACE, so TACE was no longer possible. It shows that hepatic resection can be performed by maximally preserving the remaining liver parenchyma through VTLR and securing minimal surgical margin.

\section{CONFLICT OF INTEREST}

No potential conflict of interest relevant to this article was reported.

\section{ACKNOWLEDGMENTS}

This article was submitted as a masters thesis by Hyung Won Kim, co-author.

\section{REFERENCES}

1. Buell JF, Cherqui D, Geller DA, O'Rourke N, Iannitti D, Dagher I, et al. The international position on laparoscopic liver surgery: the Louisville Statement, 2008. Ann Surg 2009;250:825-30.

2. Alkhalili E, Berber E. Laparoscopic liver resection for malignancy: 
a review of the literature. World J Gastroenterol 2014;20:13599606.

3. Kaneko H, Takagi S, Shiba T. Laparoscopic partial hepatectomy and left lateral segmentectomy: technique and results of a clinical series. Surgery 1996;120:468-75.

4. Sasaki A, Nitta H, Otsuka K, Takahara T, Nishizuka S, Wakabayashi G. Ten-year experience of totally laparoscopic liver resection in a single institution. Br J Surg 2009;96:274-9.
5. Yoon SY, Kim KH, Jung DH, Yu A, Lee SG. Oncological and surgical results of laparoscopic versus open liver resection for HCC less than $5 \mathrm{~cm}$ : case-matched analysis. Surg Endosc 2015;29:2628-34.

6. Chen MS, Li JQ, Zheng Y, Guo RP, Liang HH, Zhang YQ, et al. A prospective randomized trial comparing percutaneous local ablative therapy and partial hepatectomy for small hepatocellular carcinoma. Ann Surg 2006;243:321-8. 